\title{
Transparency and Termination in Group Psychotherapy: A Resident's Perspective
}

\author{
Althea Donovan, MD \\ Jefferson Medical College, Philadelphia PA
}

Follow this and additional works at: https://jdc.jefferson.edu/jeffjpsychiatry

Part of the Psychiatry Commons

Let us know how access to this document benefits you

\author{
Recommended Citation \\ Donovan, MD, Althea (1988) "Transparency and Termination in Group Psychotherapy: A Resident's \\ Perspective," Jefferson Journal of Psychiatry. Vol. 6 : Iss. 2 , Article 8. \\ DOI: https://doi.org/10.29046/JJP.006.2.006 \\ Available at: https://jdc.jefferson.edu/jeffjpsychiatry/vol6/iss2/8
}

This Article is brought to you for free and open access by the Jefferson Digital Commons. The Jefferson Digital Commons is a service of Thomas Jefferson University's Center for Teaching and Learning (CTL). The Commons is a showcase for Jefferson books and journals, peer-reviewed scholarly publications, unique historical collections from the University archives, and teaching tools. The Jefferson Digital Commons allows researchers and interested readers anywhere in the world to learn about and keep up to date with Jefferson scholarship. This article has been accepted for inclusion in Jefferson Journal of Psychiatry by an authorized administrator of the Jefferson Digital Commons. For more information, please contact: JeffersonDigitalCommons@jefferson.edu. 


\title{
Transparency and Termination in Group Psychotherapy: \\ A Resident's Perspective
}

\author{
Althea Donovan, M.D.
}

\section{INTRODUCTION}

Termination has been seen as a difficult and complex process in group psychotherapy. Although termination of group members has been explored, little is written on the subject of the therapist's termination; i.e., in the case of a group which continues after the therapist departs. This circumstance must occur frequently, however, especially since $91 \%$ of psychiatric programs, (Yalom (1985) citing Pinney) have at least one year of group psychotherapy training. This implies that group therapist termination must occur on a regular basis at some training programs. Even so, there are no specific guidelines or more general exploration of an inexperienced therapist's terminating with groups, including the special case of psychiatric residents.

McGee (1972) and Yalom (1985) both note a high degree of resistance to the termination of any member, and especially of the therapist. What therapeutic tools should the therapist use to counter group resistance? Clarification, observation, and interpretation, may be supplemented, according to Yalom (1985), by the judicious use of therapist transparency. There remains, however, a significant degree of controversy over the use of therapist transparency in group psychotherapy in the literature. In the clinical experience of the author which is described here, therapist transparency was useful to help the group begin the process of termination and warrants further examination.

\section{TRANSPARENCY AND TERMINATION IN GROUP PSYCHOTHERAPY LITERATURE}

The term "therapist transparency" is used only infrequently in individual psycho-analytic psychotherapy and is not clearly defined in relation to group psychotherapy. "Transparency" is used interchangeably at times with the term "self-disclosure". Transparency has been described by Dies (1976) as an openness on group process and outcome. Yalom (1985) describes it as how open, free, and honest the therapist can be. A lack of a concrete definition probably arises from the lack of study of this area and an inherent controversy in the field over the issue of therapist transparency.

Dies (1972) discusses the spectrum from one position to its opposition. $\mathrm{He}$ 
mentions the traditional psychoanalytic psychotherapy position: that a relatively detached, impersonal, and objective approach to group psychotherapy leadership is the appropriate one. The other end of the spectrum, "that unalloyed expressiveness and full scale self-disclosure are essentials for learning" is contrasted, citing Liebeman, Yalom, and Miles (1973).

In Dies (1976) earlier work, he came to the conclusion that expressing certain normal external experiences such as loneliness, positive strivings, and fears was constructive but that strong negative disclosures, such as frustration and boredom with the group, or anger towards a group member, were destructive. Other important variables, according to Dies $(1976,1977)$ are the specific type of group, phase of group development, content of the "transparent" verbalization, and leadership style.

The timing of the self-disclosure is an important factor; the same disclosure which would be more destructive earlier in the group may be more constructive the longer the group has met. The specific type of group and it's expectations is another factor. Self-disclosure by leaders in encounter groups is acceptable much earlier in this type of group than it would be in a group experience for exploring interpersonal conflicts. Some self-disclosures, such as the expression of conflicts by the leader similar to the group's, may cause the group to view him as emotionally unstable.

Dies finally concludes (1977) that no generalizations are appropriate to make concerning therapist transparency, and agrees with Yalom's (1985) position that it should not be romanticized, such that "it becomes a functional autonomy, an end rather than a means to an end" (Yalom, 1985). Both authors propose that openness or transparency is but one of the many interventions or tools available to the group leader, and timing, content, and reasoning are important variables.

As noted previously, termination of the therapist is another area that needs further exploration. McGee (1974) notes that therapist termination has been scarcely examined. In his paper, he defines therapist termination as meaning that the therapist terminates with the group while some attempt is made for the group to continue. He also delineates six different levels of therapist termination; the first level of termination is the abrupt flight of the therapist in the group's initial stages. A second level of termination is the therapist who begins to drop out and misses sessions. A third level is the abrupt departure of a therapist after the group has met for a length of time. All of the first three levels are destructive to the group, inappropriate, and stem from the therapist's unresolved counter-transference issues in the group, in supervision, or with the co-therapy structure.

A fourth level of terminations is the short-term or time-limited group. McGee proposes that termination of the therapist may be denied because of the simultaneous termination of the group. The fifth level is that which occurs at training institutes where training therapists move in and out of groups. He believes that this is rarely worked out even when the group has a healthy 
capacity. Finally, the sixth level of termination is a change in geography, job, or illness. These second group of terminations can be worked through if the group is adequately prepared.

Another important issue in itself is the termination of the co-therapy relationship, which McGee (1972) says provokes many feelings on the part of the remaining, as well as the departing therapist. He again notes that this issue may be denied. Both the group and remaining co-therapist may have intense feelings of abandonment, dissolution, and loss accompanied by feelings of anger, guilt, and resentment, thus leading to a large amount of reluctance and denial (McGee, 1974). In discussing termination of the whole group, Yalom (1985) says that the therapist must repeatedly call the members attention to the impending termination. Avoidance of this issue may be extreme to the point of group absences.

Both authors note difficulty on the part of the therapist with termination; whether it is a member or themselves, they will experience a loss. McGee (1974) also notes feelings of destructivess, guilt, anxiety, and omnipotence versus helplessness relating to whether the group can continue without the therapist.

In the relationship of transparency to termination, McGee (1974) and Yalom (1985) advise that the therapist be open about their own feelings about the impending separation, to facilitate the group's process of termination. Neither author clearly discusses the effect of the therapist's experience on termination, or whether their experience has been a factor in their denial or openness about their feelings during termination.

\section{CLINICAL PRESENTATION OF A THERAPIST'S TERMINATION}

To illustrate the use of transparency to facilitate a therapist's termination, the case of an adult outpatient group at a clinic mostly staffed by psychiatric residents will be described. The therapist who was terminating had been a co-therapist of the group for two years. The group consists of five members, three males and two females, with a male psychiatric resident as the co-therapist. One patient, Steve, was the only member of a previous group which had been dissolved, despite an attempt to maintain it. Another current male member, Allen, came shortly afterwards (two years ago). Three newer members, Marty, Betty, and Dawn were added respectively, nine months, six months, and three months before the therapist's termination.

Although the outpatient clinic has a large number of individual psychotherapy patients, there is no distinct program for group psychotherapy. Most of the previous groups were formed at a resident's request. Supervision by a group psychotherapist was utilized. The group met weekly for ninety minutes, and group members were seen individually every other week. The two long standing members, Steve and Allen, who had seen the vicissitudes of low membership, and of another male co-therapist terminating with the group, viewed and passed on to the newer members that the terminating female resident was the group 
"historian." When problems or questions arose in her absence, they would advise the group to wait until she came back. The new co-therapist had been initially ignored by the group, but after several weeks was viewed as another valid leader.

The group is an evocative, cohesive, and altruistic group. Sibling and parental transferences to the other members and co-therapist are often addressed. There is a focus on improving interpersonal skills, discussing family and social difficulties, and reducing anxiety, while expressions of sadness and anger are tolerated.

The co-therapists had developed complementary roles; the female cotherapist addressed individual and group defenses while the male co-therapist pointed out more unconscious material, although both therapists include each role in their repertoire. In terms of self-disclosure, both co-therapists focus on the here and now affects and experiences in the group with little disclosure of personal experiences from outside the group. For instance, if a group member thought that a leader was being critical of them, the co-therapist would disclose what they were thinking and if they had critical thoughts or not.

The female co-therapist was aware of the significance of her termination with the group, and discussed an appropriate time frame with her supervisor. However, the group's awareness of her impending termination came earlier than expected from the group members. The following is a description of the events of this termination interwoven with a description of the group process and members.

Steve and Allen have been in the group the longest, and an intense sibling rivalry exists between them for the group's attention. Steve says that Allen takes up too much group time talking about his work, and Allen says that Steve asks too many questions. Both are from similar ethnic backgrounds and have stated that the other reminds him of his father. Steve often tells the group that Allen's problems come from his mother, and Allen gets upset when he perceives that his mother was attacked. Steve interacted with Allen less after Allen disclosed to the group, about a year ago, that he heard voices, and the whole group became less confrontative of what they called Allen's passive-aggression.

Although Steve has indirectly or directly been hostile to new members, especially older females, he formed a dyad with Marty. Both had similar intellectual interests; Marty was complimentary of Steve's intelligence, experience, and verbal skills, thus appealing to Steve's narcissism. Marty was empathic with other group members, yet Allen was too distant, Betty too depressed to respond like Steve. Marty has severe anxiety about authority figures and had a critical, explosive father. On the other hand, Steve acts as a therapist in the group using psychoanalytic terms. Often he is intellectually correct about others, but has little expression of his own affects or awareness of others'. Steve frequently thought the female therapist had critical thoughts of him, similar to his mother's rejection of him because of a handicap. He would often act like the good child or model patient. He became visibly upset and cried in an individual 
session when the last male co-therapist of the group left, and has terminated with several individual therapists at the clinic.

Steve and Marty began meeting outside the group, and Steve would tell his personal "analysis" of the whole group on the way to the bus. Six months before the female therapist was to terminate, he told Marty that the female therapist was due to leave. Steve had previously mentioned in the group that he wanted to leave the group once he had developed more relationships outside the group. $\mathrm{He}$ joked to Marty that he now wanted to leave before the female therapist did and it would be like "rats leaving a sinking ship"; they both began laughing hysterically. Marty had a panic attack when he got home.

Marty revealed this in his brief individual session after the subsequent group, and was advised to tell the group. Steve had not mentioned it, although he had more group experience and presumably was aware of its relevance. At that time, other members of the group were told that the female therapist would indeed be leaving in six months. Steve and Marty were reminded that although the group leaders could not control their behavior outside of group, it constituted resistance to the group, diluted the process of group, and they should bring into group what they discuss outside. Allen then admitted that he felt left out and jealous of Steve and Marty's relationship.

The termination of the group therapist was thereafter rarely mentioned in the next three months except with occasional references to the issue. The important events during this time were 1) Allen began taking medication and became more active in the group, and accepted that he had schizophrenia 2) Betty became more open about herself and her fear of being attacked by Steve, who had called her artificial and denying of sad affects, 3) Steve felt the female therapist was less critical of him, especially after the female therapist revealed she felt embarassed about wearing mismatched shoes when Steve was discussing his sense of personal embarassment. He decided to stay in group to work out his hostility towards females and revealed he had no social activities outside of group, 4) Marty became more insightful about other group members and even confronted Steve about some issues, 5) A new member, Dawn, entered the group. Sometimes the group focused on the difference in the co-therapists, and would discuss their fathers when the male co-therapist was alone with them.

The group, however, did not respond to the female therapist's repeated reminders that she would be going to leave in the next eight weeks. Dawn had a panic attack on medication, when the group was changed to a different night, at the usual time of the group. She said "welcome back" to the female therapist, who had been away and started crying about her panic attack. Marty told her that he thought that the change reminded her of the female therapist's termination; she denied this and only Steve supported him.

In the sixth session before her termination, the female co-therapist started the group by discussing her own feelings. She said she felt sad about leaving the group, that it was important to her. Although she was a leader in the group, that could be a lonely position since she was isolated by her position. Nevertheless, she felt herself to be a part of the group experience. 
This transparency yielded immediate results. Allen reported that he felt angry at the female co-therapist for leaving, and was suspicious of her because she had once placed a patient in seclusion when he was an inpatient. The therapist asked if it was because the termination would remind him of his mother's impending mortality and future separation from him, which he had mentioned multiple times. He confirmed this. Steve said he was surprised because he didn't feel so much abandoned as sad and would miss the therapist a lot.

Marty said that the female therapist was his last link to his previous therapist, who had left, so it was a double loss. Betty said she would miss the female therapist because she felt she was always there for her. Dawn only said that she was sad too. The co-therapist told the group he would miss the departing therapist as well. The group had been told previously that another female co-therapist would replace the departing one.

At the next group, Steve and Allen were vying for the group's attention. Allen said he was still angry, and Steve kept asking him what it was. Allen said he was afraid the female co-therapist could commit him. Marty was surprised when Allen abruptly relinquished the floor and turned to him angrily saying it was his turn to say something. The female co-therapist said that she felt like a mother trying to leave the house with all her children asking her to do something before she left.

The group once again began more personal disclosures about their feelings, each in turn. Marty and Steve said that the female co-therapist meant a lot, particularly in that she wouldn't let them get away with things and that she was concerned about them. Betty said she was sad because the female cotherapist had encouraged her from the beginning to speak up. Dawn said she was sad, but not like the others because of her more recent arrival. She then voiced the wish that the female co-therapist had been her individual therapist (all of the patients in the group are in individual psychotherapy). Allen looked sad but did not share much. The male co-therapist said that he would miss the female co-therapist's help. Marty was tearful when he talked about his feelings and the group supported him.

\section{DISCUSSION}

From the clinical presentation of the group, it appears that the female therapist's transparency about her feelings of termination lead to a dismantlement of the group's avoidance and resistance to working through the therapist's termination. Although the patients have a variety of defenses and varying ability to explore termination, it appears that most of the group achieved a personal disclosure of their feelings of loss, abandonment, and anger, and consciously examined the issue.

About the issue of therapist transparency, Yalom (1985) and Dies (1976) found that the effect of transparency is dependent on the length of the group and type of disclosure. Yalom (1985), describes a process in which the therapist's 
image evolves from a more neutral stance, evoking transference, to a more self-disclosing one which corrects distortions. In this paradigm, therapist transparency should be most evident during termination. The type of self-disclosure is important as well; no devaluation of the group should occur, such as inappropriate terminations or disclosures of negative feelings indicating a narcissistic withdrawal of the therapist.

The group views the therapist as a mother symbol (Grotjaln, 1983) and indeed each group member had a strong maternal transference to the female co-therapist. Steve, at one point, had seen the female therapist as the rejecting "bad" mother. Marty's remarks pointed out what he felt was the critical concerns of the female therapist (like a mother). Betty mentioned that the female co-therapist was “always there." Allen's anger was similar to his anger at his mother from whom he wants constant attention and gratification, indicating his difficulties in early development and primitive defenses. Dawn's wish to have a female therapist may indicate her wish to return to her mother as well.

Kauff (1977) theorizes that the termination process may be similar to the separation and individuation phase of development, that "the nature and outcome of early separation from the mother determines the adult's subsequent experience with termination". She also points out that the mother/therapist cannot herself be clinging and has to be comfortable with the child's needs to separate at times. Thus it may be that the therapist's self-disclosure was an indication of her comfort and was the signal for the group to begin separation.

The female co-therapist also discussed her feelings of counter-transference with her supervisor and personal therapist; her sense of loss and a realization of her own strong maternal feelings in general. She and her co-therapist discussed her leaving the group, residency, and their hopes of maintaining a friendship.

\section{SUMMARY}

Transparency and termination in group psychotherapy, in terms of the therapist, are two processes whose relationship have not been fully explored. The clinical case of termination presented falls into McGee's (1976) description of a fifth level of McGee's termination involving institutions. In contrast to what he described, it was approached and worked through. Since this termination was more appropriate, it can be inferred that the therapist's use of transparency was an important factor, supplementing the understanding of transference and countertransference. Another hypothesis is that such use of transparency may be comparatively minimal at training institutions, perhaps overall or specifically during termination. This leads to the additional questions of how the use of transparency is related to the therapist's level of experience, and whether transparency is always a necessary part of termination.

Even though inexperienced therapists terminating with groups at training institutions may be a common occurrence at psychiatric residencies, little is known about the above factors. Many questions still exist: How is it different for 
a training therapist to terminate? What is the institutional views of transparency and termination and how do they affect the trainee? How does the resident's personal therapy affect the outcome? Since these difficulties arise in the training period, if not addressed, they may lead to unresolved dissatisfaction with group psychotherapy and less rigorous training. These questions warrant further study to enhance the education of psychiatric residents in group psychotherapy.

\section{REFERENCES}

1. Dies RR, and Cohen: Content considerations in group therapist self-disclosure. Int J Group Psychother 26:71-88, 1976

2. Dies RR: Group Therapist Transparency: A critique of therapy and research. Int J Group Psychother 27:177-200, 1977

3. Grotjahn M: The Qualities of the group psychotherapist, in Comprehensive Group Psychotherapy ed. Kaplan HI and Sadock BJ. Baltimore, Williams and Wilkins, pp. 294-300, 1983

4. Kauft RF: The Termination process: Its relationship to the separation-individuation phase of development. Int J Group Psychother 27:3-18, 1977

5. McGee TF: Therapist termination in group psychotherapy. Int J Group Psychother $24: 3-12,1974$

6. McGee TF, Schuman BN, and Racusen F: Termination in group psychotherapy. Am J Psychother 24:521-532, 1972

7. Yalom ID: The Theory and Practise of Group Psychotherapy. New York, Basic Books pp. 226, 368-374, 1985 